\title{
Evaluation of Accidental Atmospheric Releases of Chlorine and Butane from a Mobile Source Using ALOHA and MARPLOT
}

\author{
Noura Mohammad Al-Sarawi \\ Department of Civil and Environmental Engineering, Florida International University, Miami, USA
}

Email address:

nalsa003@fiu.edu

To cite this article:

Noura Mohammad Al-Sarawi. Evaluation of Accidental Atmospheric Releases of Chlorine and Butane from a Mobile Source Using ALOHA and MARPLOT. American Journal of Environmental Protection. Vol. 6, No. 6, 2017, pp. 144-155. doi: 10.11648/j.ajep.20170606.12

Received: November 16, 2017; Accepted: November 24, 2017; Published: January 17, 2018

\begin{abstract}
The purpose of this paper is to evaluate the extend of the threat zone of two mobile accidental atmospheric releases of chlorine and butane on the I-95 Highway by estimating the downwind dispersion of the chemical plumes using the numerical model ALOHA (Area Locations of Hazardous Atmospheres) and by graphing the boundaries of the threat zone using MARPLOT (Mapping Application for Response, Planning, and Local Operational Tasks). In addition, to assess the risk of exposure at two points of interest from the chlorine accident, and to measure the extent of the flammable zone; the area where a flash fire or a vapor cloud explosion could occur at some point after the release begins, resulting from the butane accident. Moreover, the aim is to study the stability class effect on indoor and outdoor concentrations and its effect on distance of the flammable zones. The paper conclude that the stability class has a significant effect on the prediction of the size of the toxic threat zone under different atmospheric dispersion conditions. In addition, the size of the area impacted after a chemical release depends on the characteristics of the chemical along with the meteorological and atmospheric conditions.
\end{abstract}

Keywords: Hazardous, Mobile Accidents, Atmosphere, Chlorine, Risk Analysis, Numerical Model

\section{Introduction}

Over one million hazardous material shipments are carried mostly by trucks, containing toxic and flammable liquids or gases daily in the United States [1]. According to the U.S. Department of Transportation Pipeline and Hazardous Materials, 4,533 in transit accident, 289 in transit storage, 3,292 loading, and 8,361 unloading spills occurred only in
2016 (Table 1) [13]. Highway accidental spills may cause severe harmful effects on people exposed instantaneously to the release, resident living nearby, and even kids attending schools near the area. Numerical dispersion models and the prediction of fate and transport of chemicals released into the atmosphere is a very crucial research area because of the threats on human health and the environment accompanied by accidental release of hazardous substances.

Table 1. Highway HAZMAT Summary by Transportation Phase in 2016.

\begin{tabular}{llllll}
\hline Transport Phase & Incidents & Hospitalized & Non-Hospitalized & Fatalities & Damages \\
\hline In transit & 4,533 & 1 & 22 & 7 & 1 \\
In transit Storage & 289 & 1 & 0 & $\$ 36,084,608$ & \\
Loading & 3,292 & 2 & 20 & 8876,652 & 0 \\
Unloading & 8,361 & 9 & $83,183,282$ & 0 & $\$ 3,511,812$ \\
\hline
\end{tabular}

The numerical dispersion model ALOHA is a user-friendly Gaussian approach used to estimate the downwind dispersion of a chemical cloud based on the toxicology and physical characteristics of the released chemical, atmospheric condition, and specific circumstances of the accidental release [11]. ALOHA was developed by the United States Environmental Protection Agency and the National Oceanic and Atmospheric Administration to assist chemical emergency planners and responders. It can simulate the dispersion for over 900 chemicals and is primarily used in the 
simulation of accidental release of hazardous substances and the dispersion of chemical vapor [9]. ALOHA allows for the source to be defined in one of four ways (direct source, puddle source, tank source, or pipe source) in order to model various accident scenarios. ALOHA deals specifically with human health hazards associated with inhalation of toxic chemical vapors, thermal radiation from chemical fires, and the effects of the pressure wave from vapor-cloud explosions [5]. Yet, ALOHA have some limitations that the user should be aware of. According to ALOHA Guidance Report, the model limitations are:

1. Results are less reliable for conditions of low wind speed or very stable atmospheric conditions.

2. Results have high uncertainty very close to the source.

3. ALOHA does not allow for one or more years of meteorological data to be input and processed so that statistical methods can be employed to determine the 50th percentile (median) or 95th percentile (unfavorable) concentration results.

4. ALOHA does not model the initial momentum of the release.

5. ALOHA does not account for the effects of fires or chemical reactions.

6. ALOHA does not account for terrain steering effects.

7. ALOHA does not model dispersion effects associated with building wakes.

8. ALOHA does not model the evaporation of chemical constituents in a mixture or solution.

9. ALOHA limits predictions to one hour after the release begins or to distances up to ten kilometers (6 miles).

10. ALOHA does not model processes that affect the dispersion of particles, such as deposition from gravitational settling [10].

The model strengths are:

1. Provide an assessment of the threat zones using information that is commonly available to respond during an emergency.

2. Designed to be easy to use so that responders can use it during a spill event.

3. Designed to minimize operator error.

4. Navigation through the model input screens is designed to be intuitive and quick.

5. User input data is checked for consistency and reasonableness scenarios.

6. Results are presented graphically.

7. Provide methods for estimating the release and volatilization rate of chemicals for many common accident scenarios.

8. Runs quickly on small computers that are easily transported and affordable for most users

9. Designed to predict hazards associated with spills of a scale that are typical of transportation accidents [10].

It is believed that the model's limitations affecting the predicted results from the simulations are:

1. The model does not account for fires and chemical reactions.

2. The model does not account for gravitational settling.
3. The model is less reliable for conditions of low wind speed or very stable atmospheric conditions.

The rest of the limitations are not to be concerned about since the study did not look at point of interest very close to the source, Miami's topography is fairly flat so there is no need to account for terrain steering effects, for both scenarios pure chemicals was choose so there is no need to model evaporation of chemical constituents in a mixture or solution, and since the release is instantaneous, there is no need for more than one hour dispersion prediction and the predicted dispersion is less than 6 kilometers. The strengths of the model can be summarized as user friendly, contains informative visuals, and designed to minimize operator errors.

The model predicts the concentration of the chemical in the atmosphere and the plume boundaries then share the resulting threat zone simultaneously with MARPLOT. Threat zone represent the area where the ground level concentration exceeds the range entered as the level of concern. MARPLOT is a mapping application that can be used with ALOHA to provide a visual of the extend of the plume using variety of base maps. The importance of ALOHA simulation results is that they provide consequence analysis and risk assessment. Results of the simulation could serve as a useful guide to create rescue plans, emergency responses, and neighborhood warnings to ensure safety of all the people in the area.

ALOHA have very powerful integral databases. It includes data files with physical, chemical, and toxicological properties for hundreds of pure chemicals and some common chemical solutions [5]. A chemical name, CAS registry number, molecular weight, and toxicological data are included for every chemical in the data file. These are the minimum data required for the Direct Source option and the Gaussian dispersion model in ALOHA. For other modeling options, such as source strength, heavy gas, and modeling for fires and explosions require more extensive datasets. Full datasets are available for about half the chemicals in the data file; the additional physical property data required were extracted from the DIPPR data compilation, a proprietary database containing physical constants and formulas for temperature dependent properties (American Institute of Chemical Engineers) [5]. Data are available for the following properties: critical temperature, critical pressure, critical volume, freezing point, normal boiling point, vapor pressure, liquid density, gas density, heat of vaporization, heat of combustion, liquid heat capacity, and vapor heat capacity. Therefore, the model accounts for all the physical and chemical difference between the chemicals.

After evaluating historical accidents and related statistical sources sponsored by the United States Department of Energy, chlorine has the highest percentage of fatality risk from exposure to spills and leaks (Figure 1). Therefore, for the purpose of this study, the first scenario involves an accident of a transport truck carrying four 62-kilograms chlorine cylinders in the truck bed. The cylinders were damaged during the collision and simultaneously release their contents. 


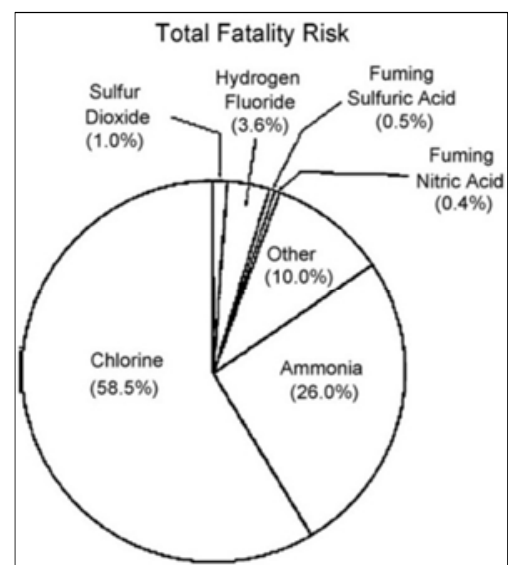

Figure 1. Distribution of Total Fatality Risk as a Result of Exposure to Spills and Leaks (Bernatik, et al. 2007).

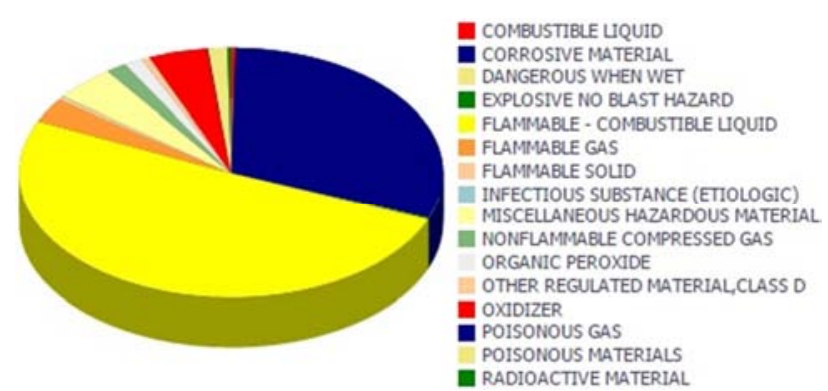

Figure 2. Incidents by Hazard Class in 2016 [7].
According to the U.S. Department of Transportation Pipeline and Hazardous Materials Intelligence Portal, accidents involve the transport of flammable-compostable liquids have the highest percent among other categories of hazard class accidents (Figure 2). Therefore, the second simulation involves an accident of transport truck that resulted in the leakage of 10,000 gallons of butane.

The objectives of this study are to evaluate the consequences of the accidental atmospheric release of chlorine on two points of interests, which are a residential area and a university campus, and to analyze the flammable threat zone resulting from the leakage of a liquefied petroleum gas (butane). In addition, is to study the stability class effect on indoor and outdoor concentrations, and its effect on distance of the flammable zones.

\section{Materials and Methodology}

\section{A. Acquisition of Meteorological Data}

The most important meteorological conditions influencing the dispersion of dangerous substances are direction and speed of wind, stability class, and air temperature. In order to simulate a real-life scenario, Miami International Airport weather radar was used to gather meteorological data. The month of interest is August. Shown in figure 3, temperature is $86 \mathrm{~F}(30 \mathrm{C})$, wind direction is $\mathrm{NW}$, and average wind speed is $9 \mathrm{mph}$ (Figure 3 ).

\begin{tabular}{|c|c|c|c|c|c|c|c|c|c|c|c|c|c|}
\hline \multirow[t]{2}{*}{ Month of year } & Jan & Feb & Mar & Apr & May & Jun & Jul & Aug & Sep & Oct & Nov & Dec & Year \\
\hline & 01 & 02 & 03 & 04 & 05 & 06 & 07 & 08 & 09 & 10 & 11 & 12 & $1-12$ \\
\hline \multirow{2}{*}{$\begin{array}{l}\text { Dominant wind direction } \\
\text { Wind probability >= } 4 \text { Beaufort (\%) }\end{array}$} & $T$ & $\nabla$ & $\nabla$ & $T$ & $T$ & $\nabla$ & $T$ & $T$ & $T$ & 4 & 4 & $T$ & $\boldsymbol{T}$ \\
\hline & 27 & 26 & 40 & 39 & 36 & 26 & 21 & 21 & 19 & 28 & 27 & 29 & 28 \\
\hline \multicolumn{14}{|l|}{ Average Wind speed (mph) } \\
\hline & 10 & 10 & 12 & 12 & 10 & 10 & 9 & 9 & 9 & 10 & 10 & 10 & 9 \\
\hline Average air temp. ("F) & 72 & 72 & 75 & 81 & 82 & 86 & 86 & 86 & 84 & 82 & 77 & 75 & 79 \\
\hline
\end{tabular}

Figure 3. Meteorological Data (windfinder.com).

B. Acquisition of Level of Contaminants (LOC)

ALOHA uses the 60-minute exposure period of AEGL (Acute Exposure Guideline Levels) as a default option for determining toxicity levels (Table 2). The model also provides the option of user specified. For the first case scenario of chlorine spill, since the release is instantaneous, it was decided to use the 10-minute exposure levels of AEGL to analyze the data with more confidence.

Table 2. Final AEGLs for Chlorine in ppm [6].

\begin{tabular}{llllll}
\hline & 10 minutes & 30 minutes & 60 minutes & 4 hours & 8 hours \\
\hline AGEL -1 & 0.50 & 0.50 & 0.50 & 0.50 & 1.0 \\
AGEL-2 & 2.8 & 2.8 & 2.0 & 0.50 & 0.71 \\
AGEL-3 & 50 & 28 & 20 & 7.1 \\
\hline
\end{tabular}

C. Tank and Cylinder Dimensions

Chlorine Cylinder - "The most common sizes are $100 \mathrm{lb}$ $(45 \mathrm{~kg})$ and $150 \mathrm{lb}(68 \mathrm{~kg})$ " (Figure 4). To resembles a reallife scenario, it was supposed to be more realistic that not all the material is disposed due to the accident. It was decided that the accident will result in $62 \mathrm{~kg}$ of chlorine release.
Butane Tank - According to the HAZMAT Guide for First Responders, butane tank truck capacity is 11,500 gallons (Figure 5). To resemble a real-life scenario, not all the material will be disposed due to the accident. It was also decided that the accident will result in 10,000 gallon of butane release. 


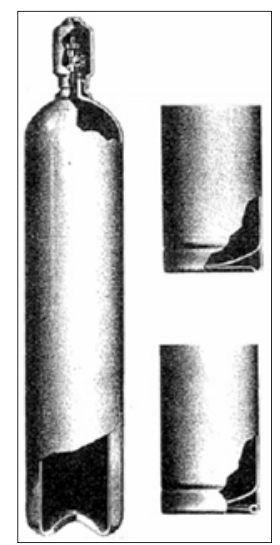

Figure 4. Chlorine Cylinder (3)

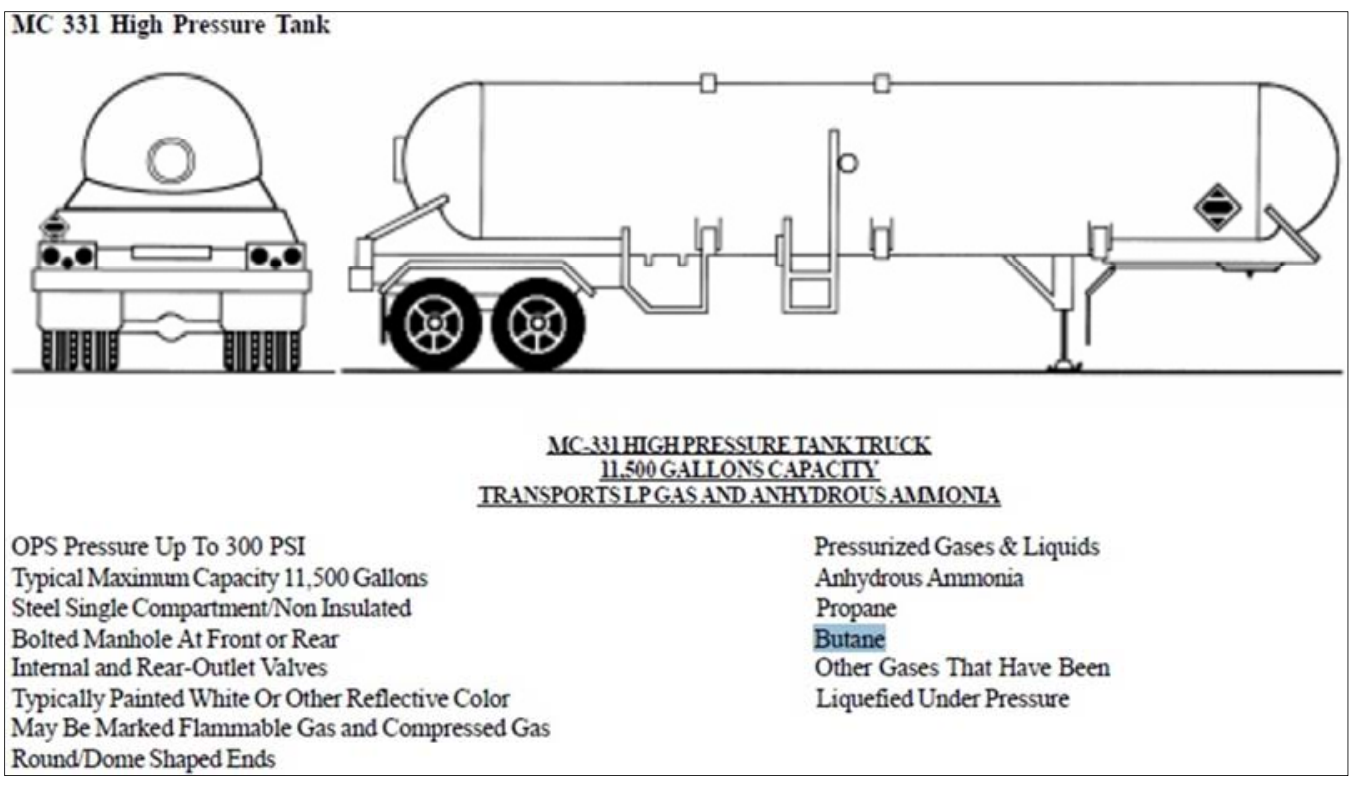

Figure 5. Butane Tank Truck Capacity [12].

\section{Data Input}

Location, Date and Time- From the location tab under site data, Miami, Florida was chosen (Figure 6). From the date and time tab (Figure 7), August 15, 2016 at 5pm was chosen as the time the accidents occur.

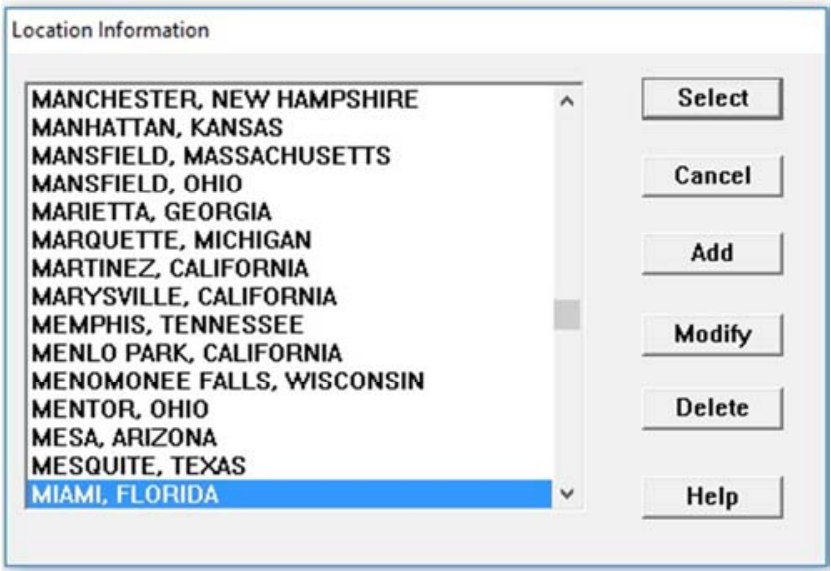

Figure 6. Location Information.

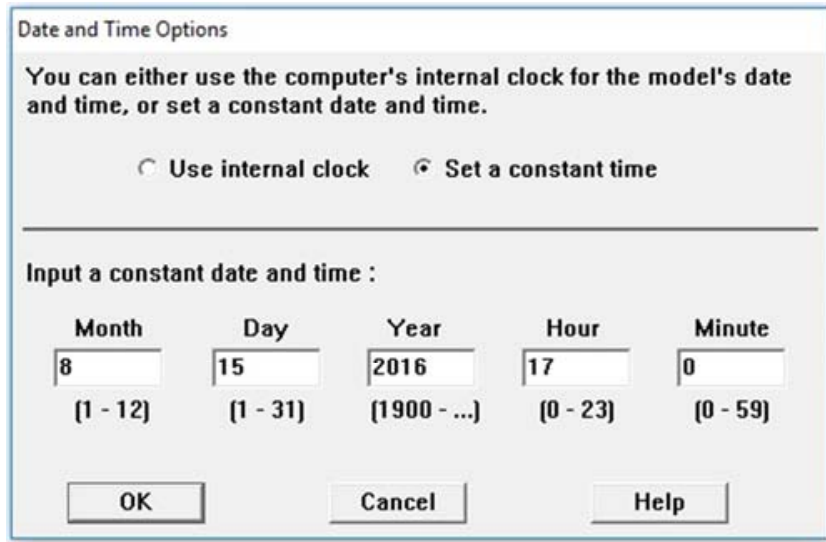

Figure 7. Date and Time.

Atmospheric Conditions: Based on meteorological data presented in figure 3,9 $\mathrm{mph}$ wind speed and $\mathrm{NW}$ wind direction was chosen (Figure 8). The maximum temperature the model can represent is $29^{\circ} \mathrm{C}$, which is very close to the $30^{\circ} \mathrm{C}$ average temperature according to the radar. The ground 
roughness was selected to be urban as the accident occurred on the highway. Clear sky was selected for cloud cover as it is usually sunny in Miami in the summer time.

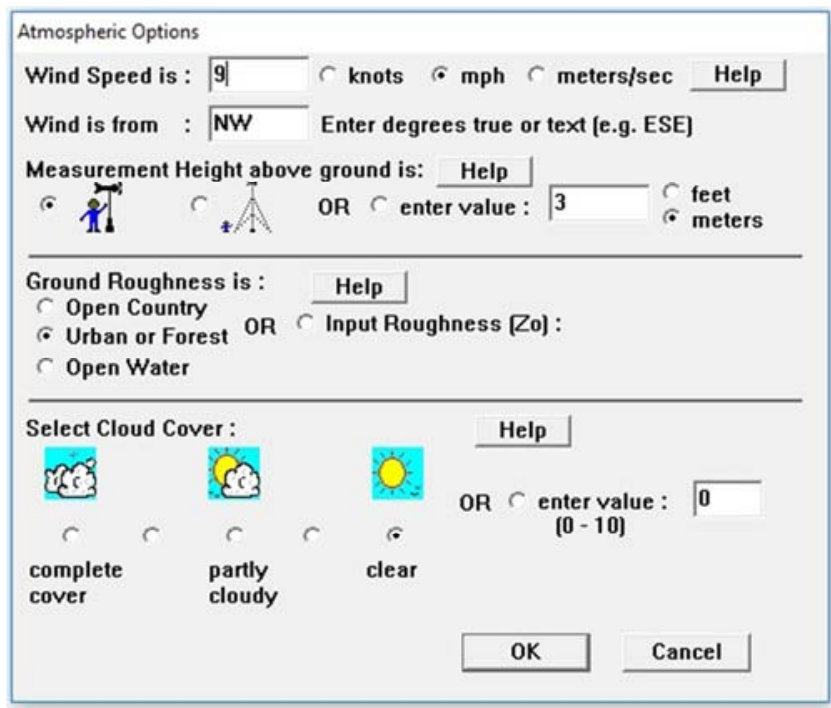

Figure 8. Atmospheric Conditions.

\section{E. Infiltration Building Parameter}

For the point source analysis, the contamination level was examined at a residential area and a University Campus with single storied building (building parameter) with sheltered surroundings (trees, bushes, etc.) for the residential area (house), and double storied building with sheltered surroundings for the University Campus.

F. Source Setup

Scenario A: As mentioned earlier, the first scenario involves an accident of a transport truck carrying four 62kilograms chlorine cylinders in the truck bed. The cylinders were damaged during the collision and simultaneously release their contents. The first step is to choose chlorine (Figure 9) in its pure form as the chemical that will be released from the truck.

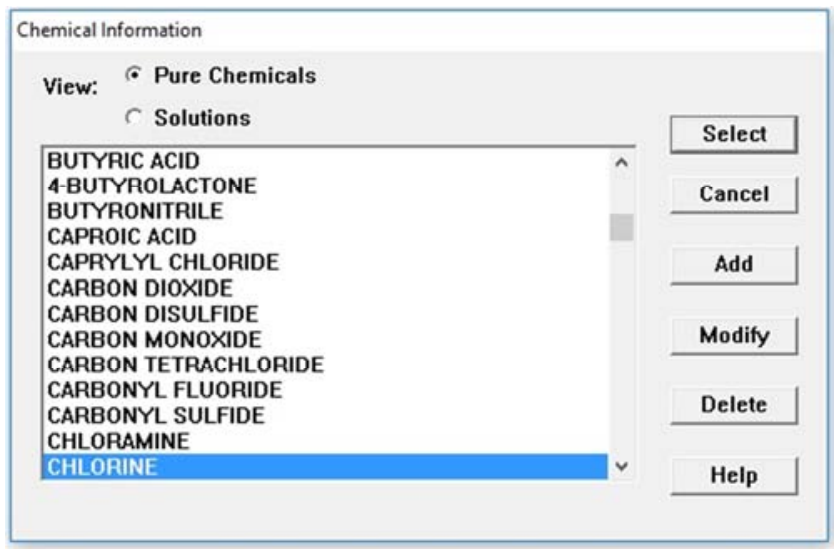

Figure 9. Scenario (A) Chemical Information.

From the setup menu, direct source was chosen for this scenario. A total of 250 kilograms (Figure 10) were released into the atmosphere instantaneously.

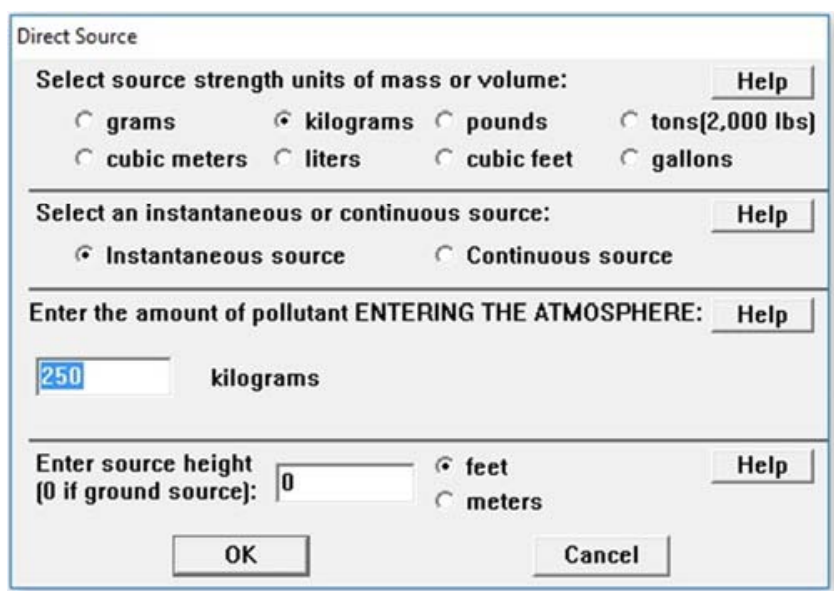

Figure 10. Scenario (A) Release Specifications.

Scenario B: The second simulation involves an accident of transport truck that resulted in the leakage of 10,000 gallons of butane (Figure 11). The tank is 45 feet long and has a diameter of 6.15 feet.

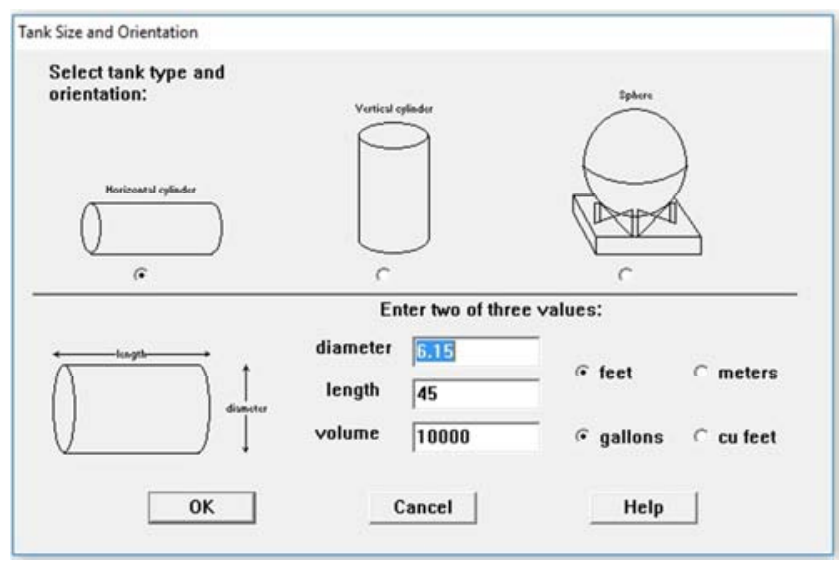

Figure 11. Butane Tank Size and Orientation.

Figure 12 shows the butane state and temperature, and figure 13 shows the chosen failure type, which is leaking tank containing chemical that is not burning as it escapes to the atmosphere.

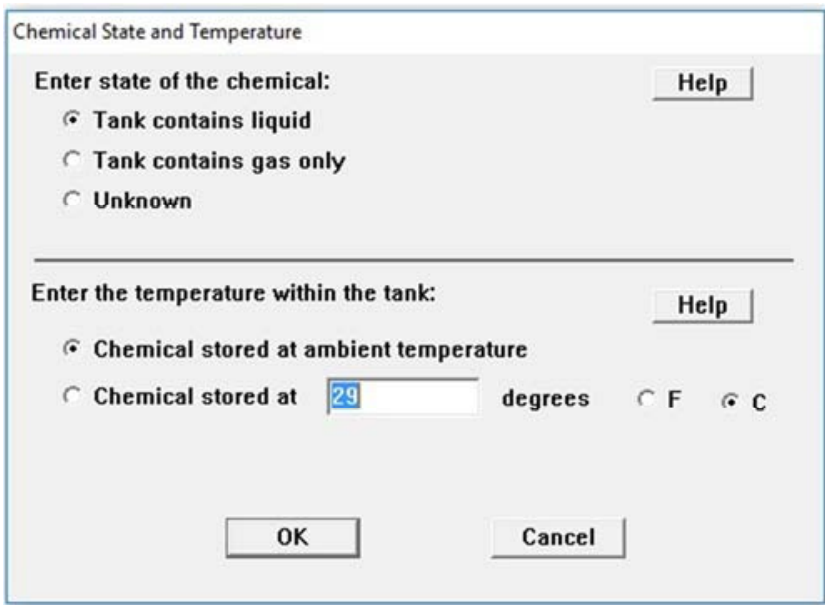

Figure 12. Butane State and Temperature. 


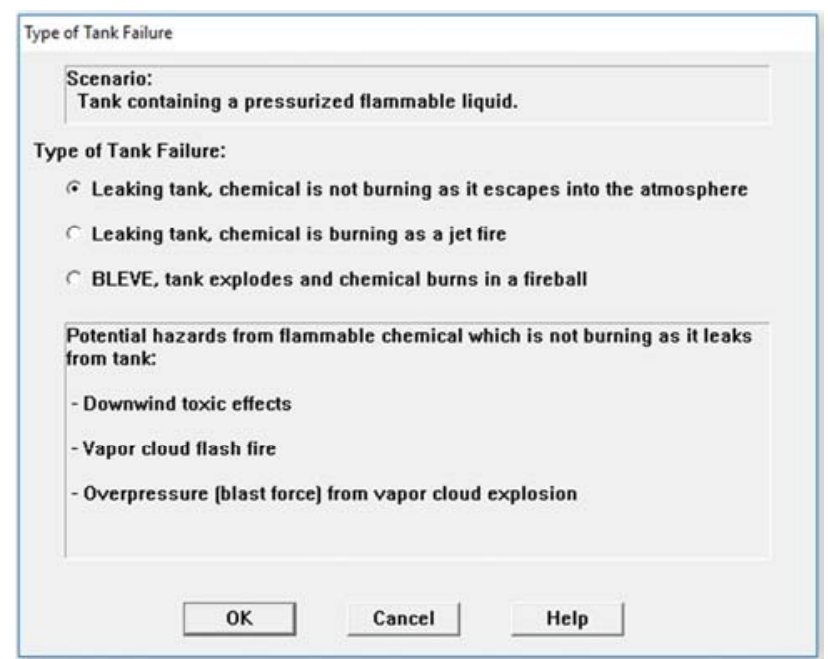

Figure 13. Type of Butane Tank Failure.

Figure 14 shows the cause of the leak, which is a rectangular opening 20 inches long and 0.5 inches wide. Table 3 shows a summary of the two scenarios.

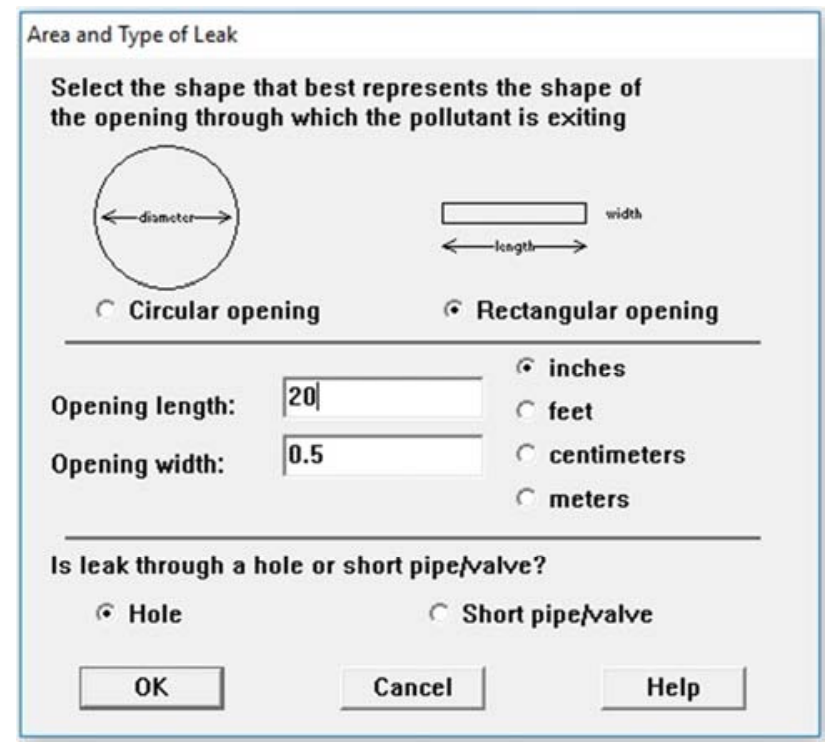

Figure 14. Area and Type of Butane Leak.

Table 3. Summary of the Two Scenarios.

\begin{tabular}{lll}
\hline Scenario & A & B \\
\hline Chemical & Chlorine & Butane \\
Total Amount Released & $250 \mathrm{~kg}$ & 10,000 gallons \\
Model of Release & Direct Release & Leaking tank \\
Temperature & $29 \mathrm{C}$ & $29 \mathrm{C}$ \\
Humidity & $50 \%$ & $50 \%$ \\
Cloud Cover & Clear & Clear \\
Wind Speed & $9 \mathrm{mph}$ & $9 \mathrm{mph}$ \\
Atmospheric Stability Class & $\mathrm{D}$ & $\mathrm{D}$ \\
Ground Roughness & Urban & Urban \\
\hline
\end{tabular}

\section{Results and Analysis}

Scenario A

The first scenario source strength is summarized below in table 4 .
Table 4. Scenario (A) Source Strength.

\begin{tabular}{ll}
\hline Total Amount Released & $250 \mathrm{~kg}$ \\
Release Duration & $1 \mathrm{minute}$ \\
Release Rate & $4.16 \mathrm{~kg} / \mathrm{sec}$ \\
Note & This chemical may flash boil and/or \\
& result in two phase flow \\
\hline
\end{tabular}

Time duration of 10 minutes AEGLs was executed to determine the Levels of Concern (LOCs) for chlorine. Figure 15 shows the three toxic levels of concern concentrations. NOAA's Office of Response and Restoration classified the levels of concern as follows:

1. AEGL-3 is the airborne concentration, expressed as parts per million (ppm) or milligrams per cubic meter $\left(\mathrm{mg} / \mathrm{m}^{3}\right)$, of a substance above which it is predicted that the general population, including susceptible individuals, could experience life-threatening health effects or death.

2. AEGL-2 is the airborne concentration (expressed as $\mathrm{ppm}$ or $\mathrm{mg} / \mathrm{m}^{3}$ ) of a substance above which it is predicted that the general population, including susceptible individuals, could experience irreversible or other serious, long-lasting adverse health effects or an impaired ability to escape.

3. AEGL-1 is the airborne concentration (expressed as $\mathrm{ppm}$ or $\mathrm{mg} / \mathrm{m}^{3}$ ) of a substance above which it is predicted that the general population, including susceptible individuals, could experience notable discomfort, irritation, or certain asymptomatic nonsensory effects. However, the effects are not disabling and are transient and reversible upon cessation of exposure.

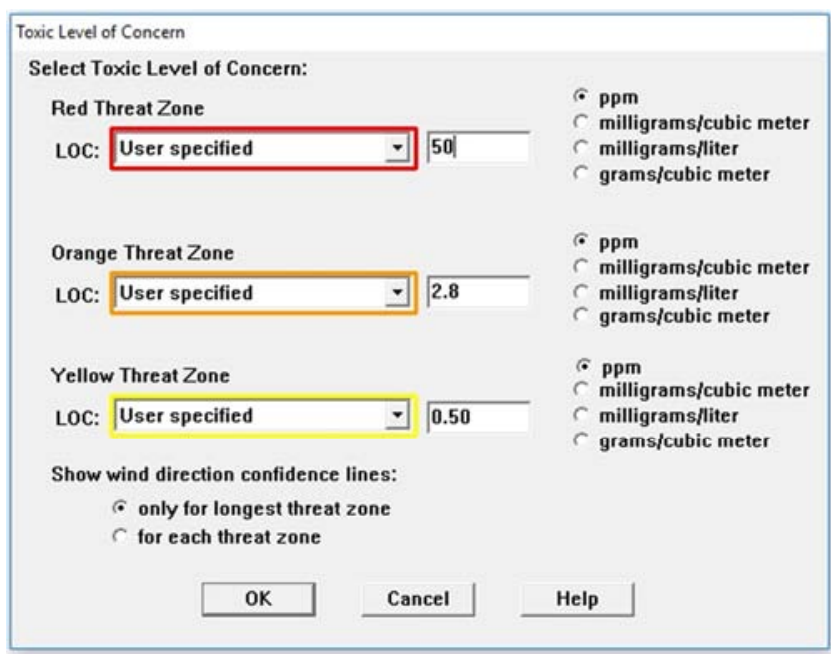

Figure 15. Scenario (A) Toxic Level of Concern.

After that, toxic threat zone graph showing the boundaries of the dispersive plume was created using ALOHA, and is shown in figure 16. It shows in the figure that the plume spreads to 3.7 miles. Table 5 summarize the results of dispersion using data from the threat zone graph. Figure 17 shows MARPLOT map of the dispersion using satellite base map. 


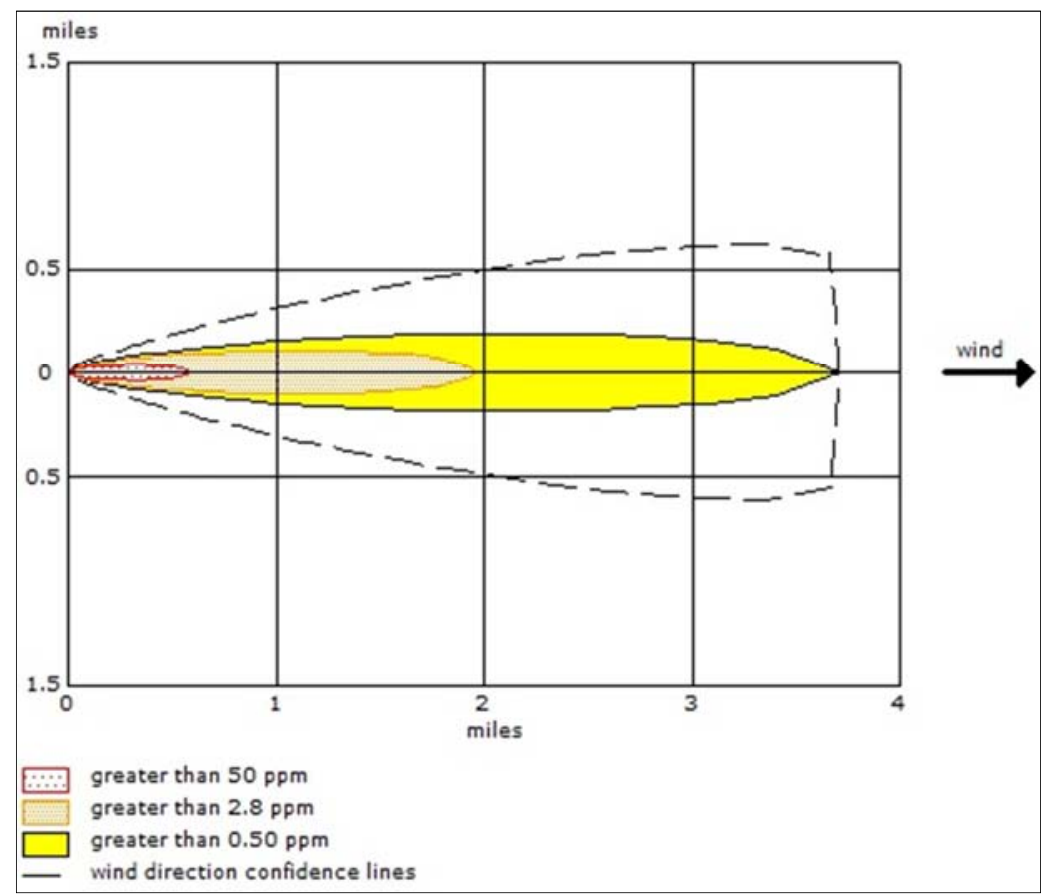

Figure 16. Scenario (A) Toxic Threat Zone.

Table 5. Scenario (A) Threat Zone Summary.

\begin{tabular}{ll}
\hline Threat Zone & Distance \\
\hline Red & 1576 yards \\
Orange & 2.2 miles \\
Yellow & 3.7 miles \\
\hline
\end{tabular}

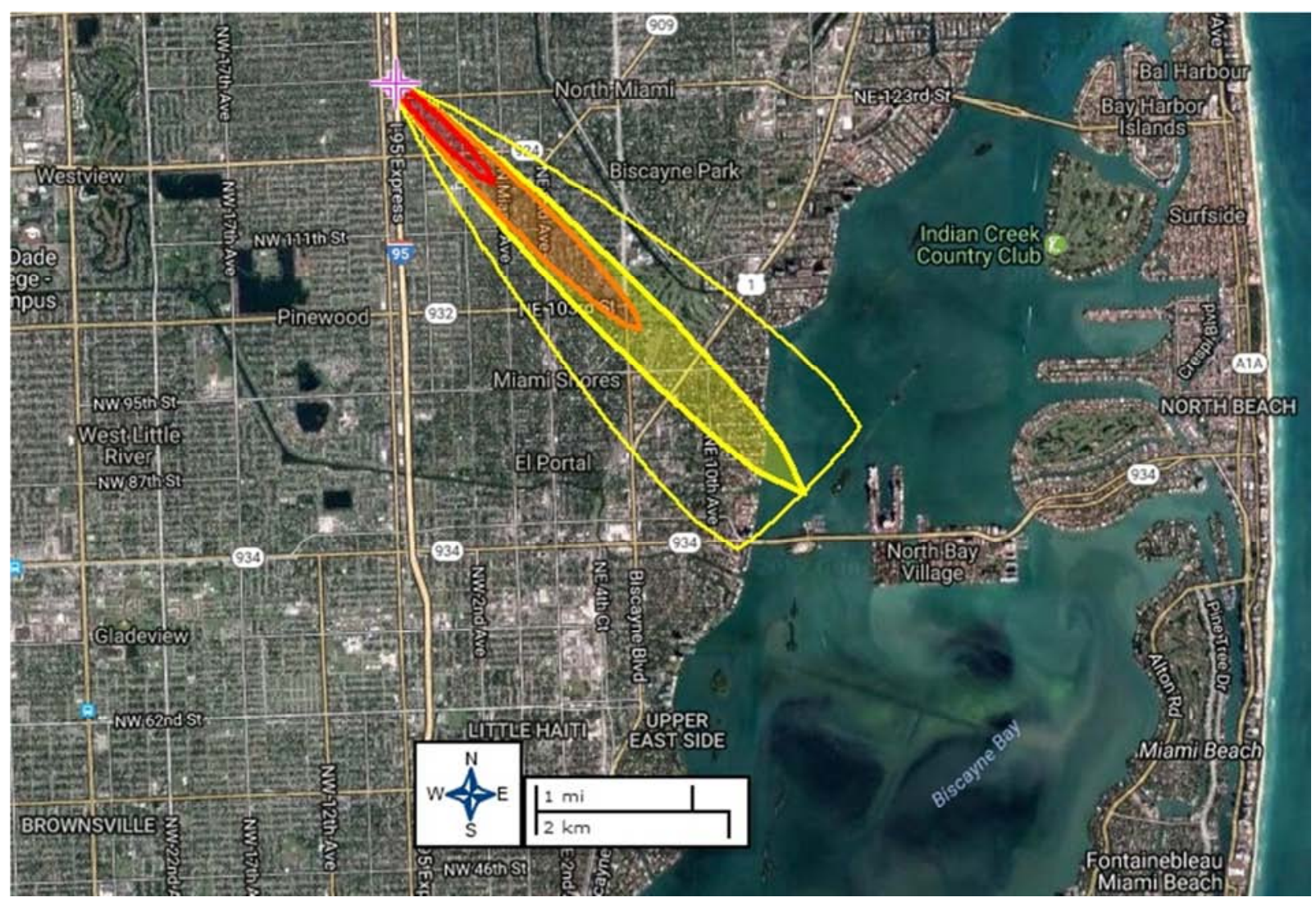

Figure 17. Scenario (A) MARPLOT. 
There is a neighborhood located in a very close proximity from the highway. MARPLOT was used to create a point of interest in this residential area to examine the severity of the exposure. Figure 18 shows the point of interest that was created, which resembles a house. By examining figure 19, you can see that the outdoor concentration line rises above zero about one minute after the release begins, then remains above zero for about 3 minutes. According to the estimates, the outdoor concentration may reach a maximum value of $177 \mathrm{ppm}$, above the 10-min AEGL-3 value for chlorine (50 $\mathrm{ppm})$. On the other hand, the estimated maximum indoor concentration at this location is $2.39 \mathrm{ppm}$, just above the 10min AEGL-1 value for chlorine ( $0.5 \mathrm{ppm})$, but very close to the 10 -min AEGL-2 value (2.8 ppm).

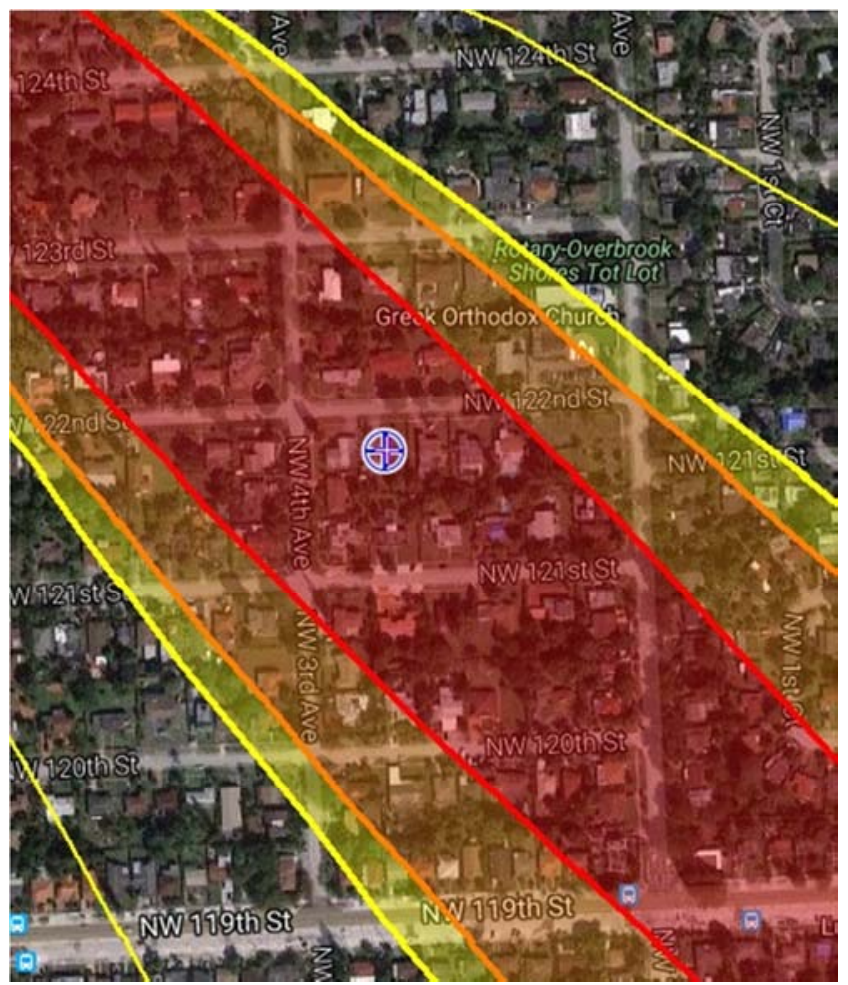

Figure 18. Scenario (A) Residential Area Exposure Threat Map.

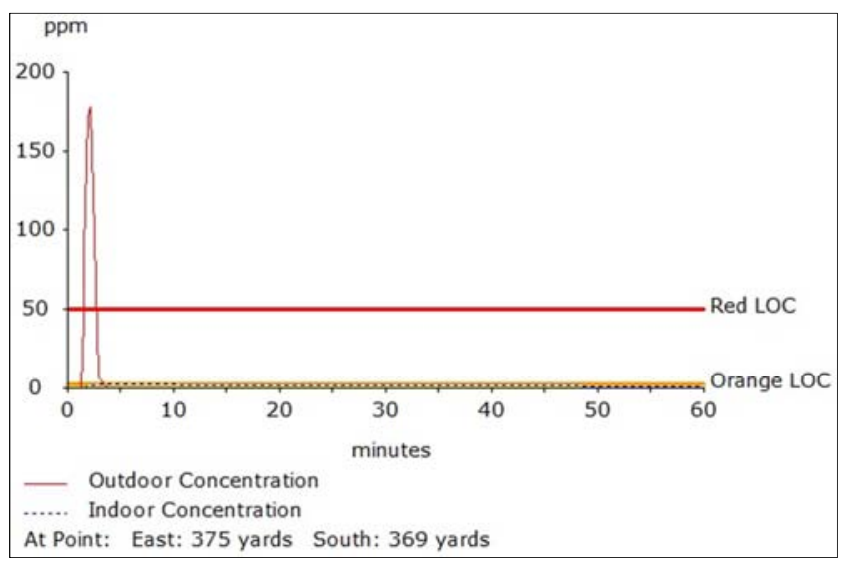

Figure 19. Scenario (A) Residential Area Threat Graph.

Barry University is also located within the boundaries of threat zone. Since Universities are also a major concern because of the presence of many students attending, it was important to look at the estimated threat on campus. Figure 20 shows the second point of interest which resembles Barry's University campus. By examining Figure 21, you can see that the outdoor concentration line rises above zero about 3 minutes after the release begins, then remains above zero for about 5 minutes. According to the estimates, the outdoor concentration may reach a maximum value of $15.3 \mathrm{ppm}$, above the 10-min AEGL-2 value for chlorine (2.8 ppm). On the other hand, the estimated maximum indoor concentration at this location is $0.267 \mathrm{ppm}$, which is below the $10-\mathrm{min}$ AEGL-1 value for chlorine ( $0.5 \mathrm{ppm})$.

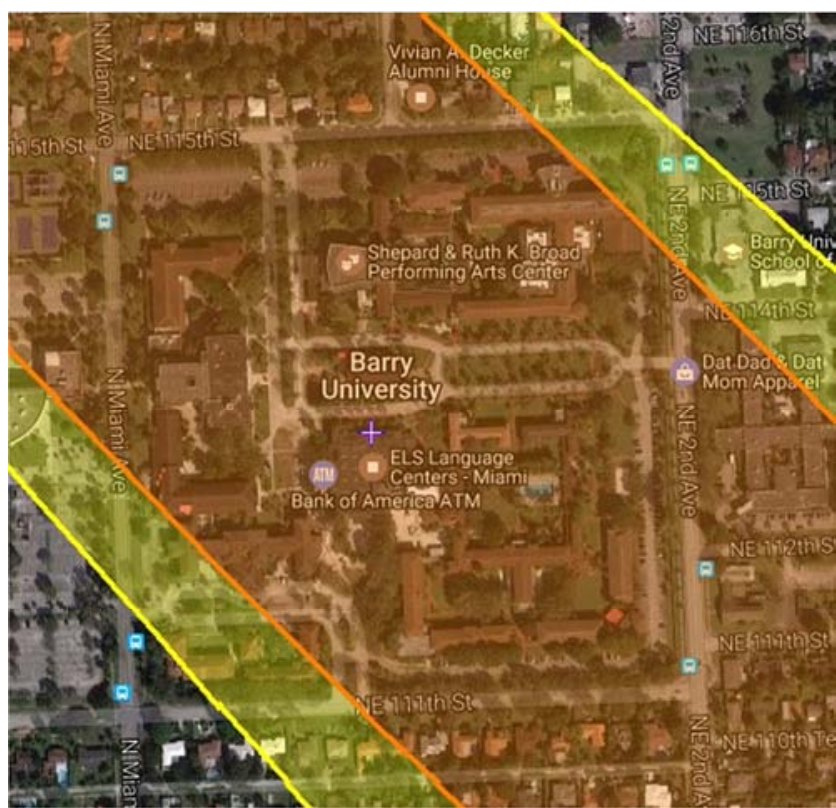

Figure 20. Scenario (A) Barry University Exposure Threat Map.

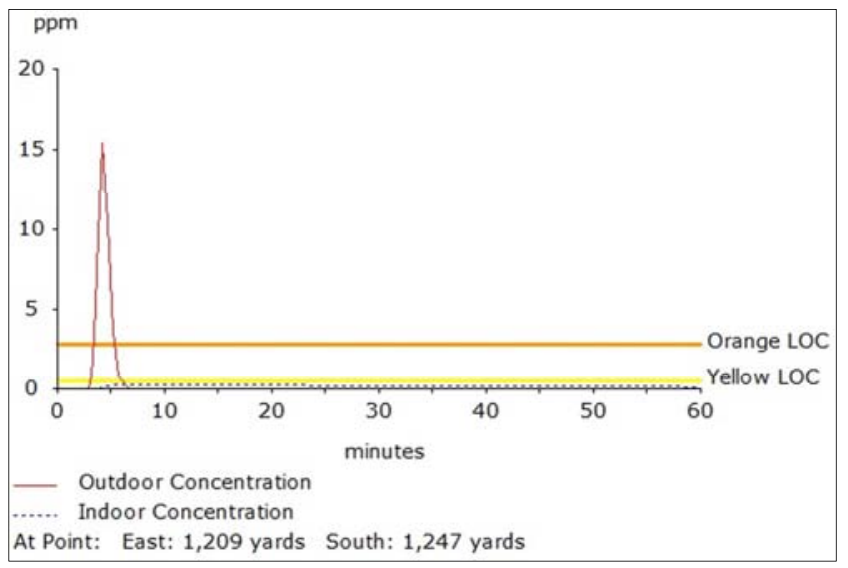

Figure 21. Scenario (A) Barry's University Threat Graph.

After analyzing the threat zone of chlorine, it was decided to look at the effects of stability classes (Table 6) on the dispersion of the chemical plume. Stability classes (A, B, C, and D) represent unstable conditions, class $\mathrm{D}$ represent neutral conditions, and classes $\mathrm{E}$ and $\mathrm{F}$ represent stable 
conditions. Stability is usually estimated as a function of wind velocity and solar radiation [8]. So, unstable atmospheric conditions, will yield high turbulence, frequent flocculation in wind directions, and strong solar radiation. On the other hand, stable atmospheric conditions, will result in low turbulence, limited flocculation in wind direction, and less solar radiation. Table 6 shows the specific state of each stability class. The comparison will be examined in this section, and discussion will follow in the Discussion and Conclusions section of this report.

Table 6. Definition of the Atmospheric Stability Classes.

\begin{tabular}{ll}
\hline Stability Class & Definition \\
\hline A & Extremely unstable \\
B & Moderately unstable \\
C & Slightly unstable \\
D & Neutral \\
E & Slightly stable \\
F & Moderately stable \\
\hline
\end{tabular}

For the purpose of this comparison, the same exact scenario was used with changing the stability class only. The simulation run was performed 6 times for each stability class, and results were tabulated and graphed as shown in table 7 and figure 22. The results show a pattern that the more stable the atmosphere, the higher and more dangerous the concentration.

Table 7. Stability Class effects on Outdoor and Indoor Concentration.

\begin{tabular}{lllllll}
\hline \multicolumn{7}{c}{ Stability Class } \\
$\begin{array}{l}\text { Concentration } \\
(\mathbf{p p m})\end{array}$ & $\mathbf{A}$ & $\mathbf{B}$ & $\mathbf{C}$ & $\mathbf{D}$ & $\mathbf{E}$ & $\mathbf{F}$ \\
\hline $\begin{array}{l}\text { Outdoor } \\
\text { Indoor }\end{array}$ & 25.3 & 38 & 56.4 & 76.9 & 91.9 & 107 \\
\hline
\end{tabular}

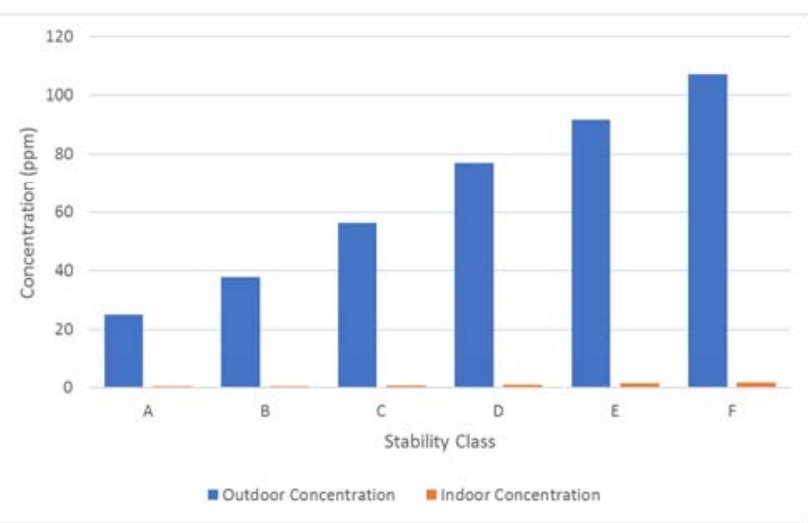

Figure 22. Stability Class Effects on Outdoor and Indoor Concentration.

\section{Scenario B}

The second scenario, involving the butane leak, source strength is summarized below in table 8 .

Table 8. Scenario (B) Source Strength.

\begin{tabular}{ll}
\hline Total Amount Released & 10,000 gallons \\
Release Duration & 8 minutes \\
Release Rate & $3,392 \mathrm{~kg} / \mathrm{min}$ \\
Note & The chemical escaped as a mixture of gas \\
& and aerosol (two phase flow) \\
\hline
\end{tabular}

It was determined to analyze the flammable area of vapor explosion for this scenario. Figure 23 shows the flammable level of concern for butane. ALOHA assumes that the threat zone from a flash fire is closely related to the lower flammability or explosive limit threat zone (ground level concentration contour) for the cloud. Based upon recommendations of the project external review team the choice was made to use $60 \%$ of the lower flammability limit as the level of concern in defining this threat zone [5].

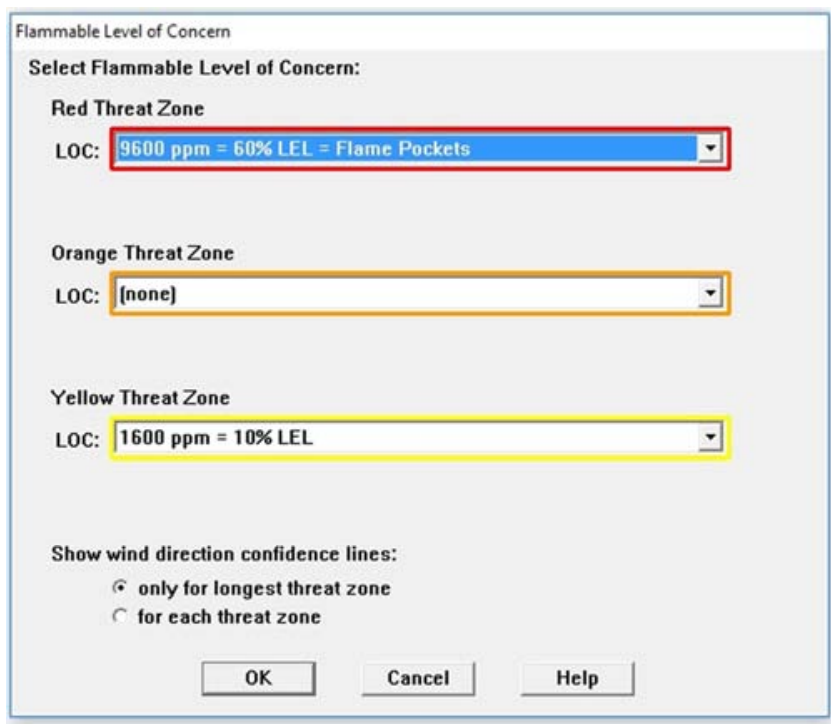

Figure 23. Scenario (B) Flammable level of Concern.

The flammable area red threat zone, which represent the $60 \%$ LEL at a concentration of $9600 \mathrm{ppm}$, is estimated to extend 169 yards downwind (Figure 24). This is the area where ALOHA predicts a flash fire or a vapor cloud explosion could occur at some point after the release begins. Figure 25 shows MARPLOT graph of the flammable threat zone of a satellite base map.

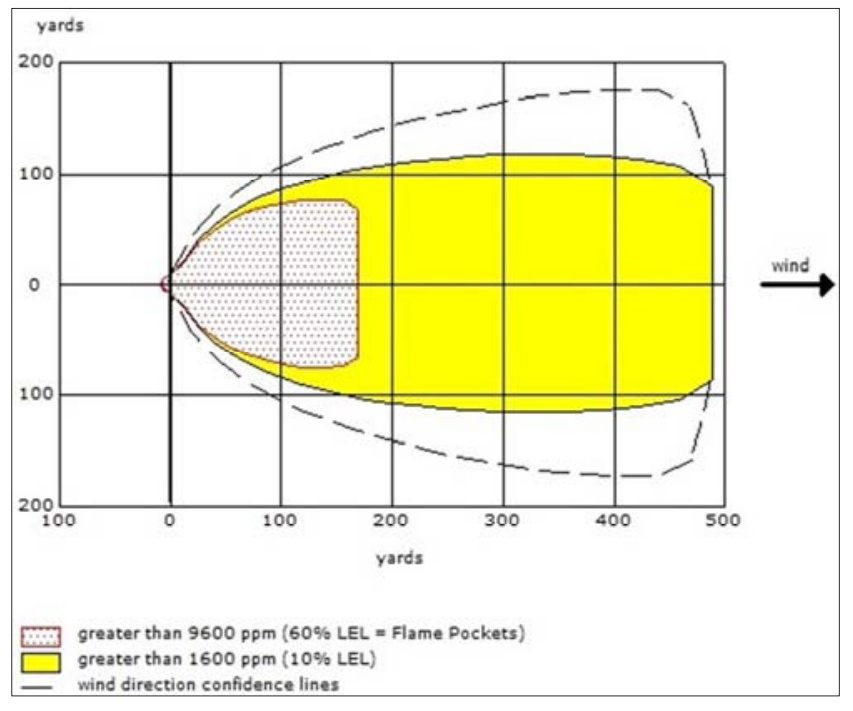

Figure 24. Scenario (B) Flammable Threat Zone Graph. 


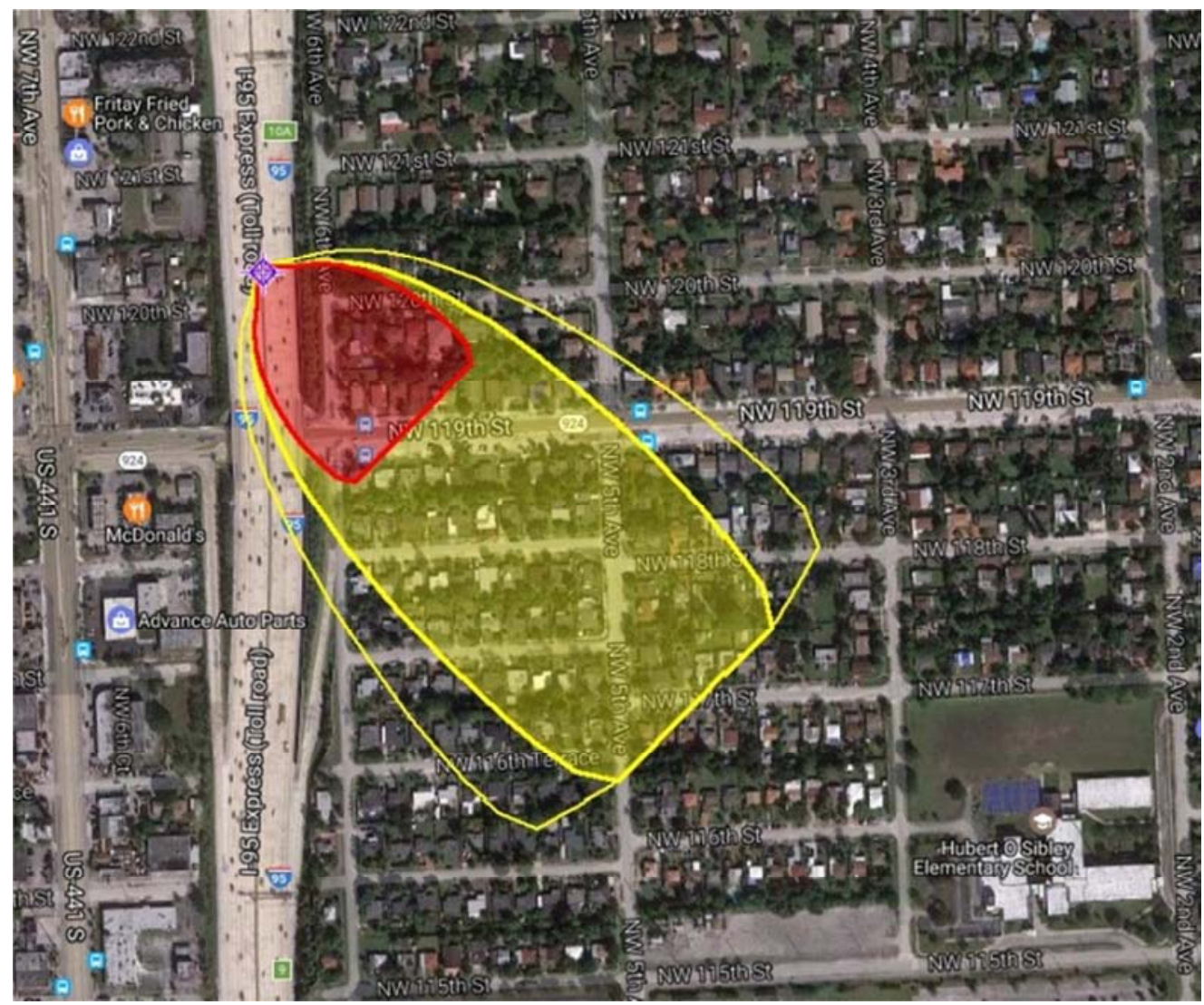

Figure 25. MARPLOT Flammable Threat Zone.

The stability class effect on the distance (Table 9) of the flammable threat zone shows similar pattern to its effect on outdoor and indoor concentrations. That is, the more stable the atmosphere, the longer the distance of the flammable zone (Figure 26).

Table 9. Stability Class Effects on the Distance of the Flammable Zone.

\begin{tabular}{lllllll}
\hline & A & B & C & D & E \\
\hline Red & 37 yards & 41 Yards & 45 Yards & 47 Yards & 50 Yards \\
Yellow & 132 Yards & 140 Yards & 150 Yards & 154 Yards & 57 Yards & 160 Yards \\
\hline
\end{tabular}

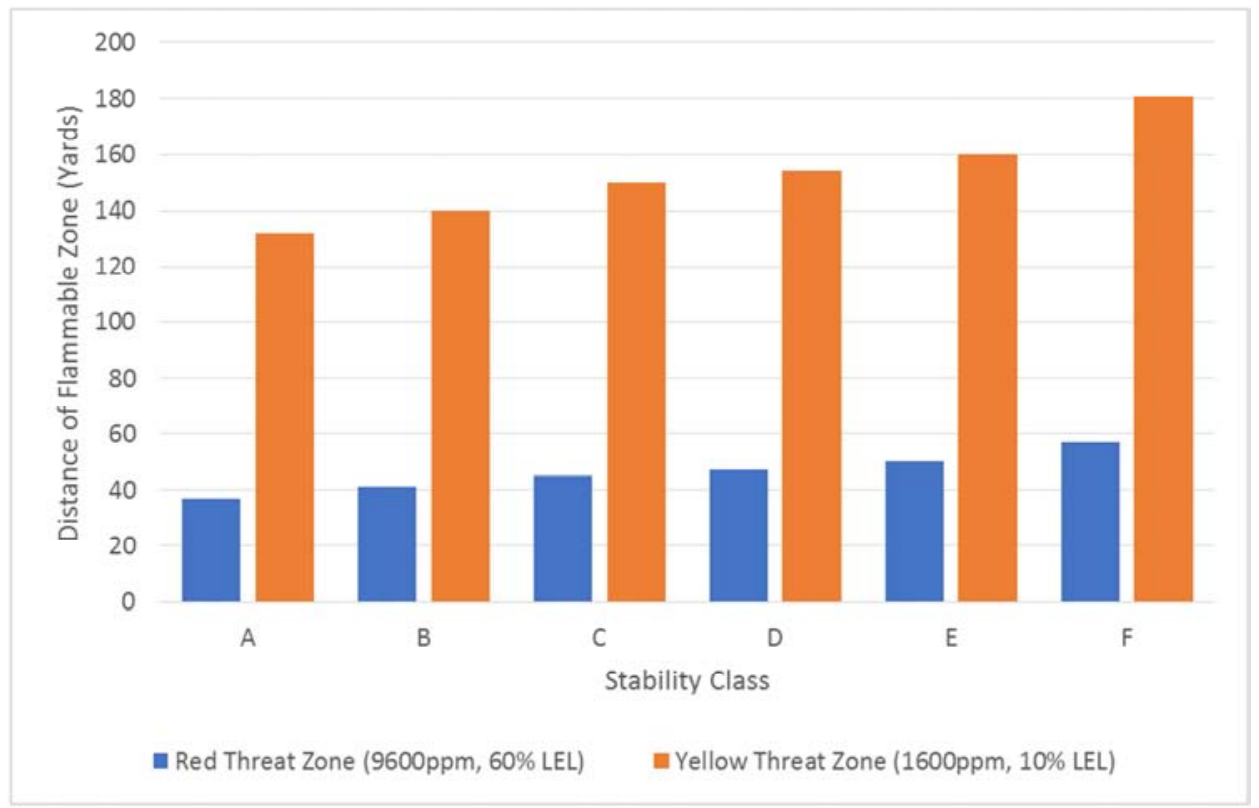

Figure 26. Stability Class Effects on the Distance of the Flammable Zone. 


\section{Discussion and Conclusions}

Scenario (A) is a direct source case of chlorine release, which allows to directly specify the amount of chemical vapors introduced into the air from a point in space. This option can be used with gasses denser than air, which is the case of chlorine. The accident simulation using ALOHA resulted in 1576 yards of red threat zone, covering a part of a residential area close to the road where the spill occurred. Being outdoor at the time the spill occurred, which means being exposed to $50 \mathrm{ppm}$ of chlorine, could result in lifethreatening health effects or death. Unfortunately, being indoor will not create a shield and dodge the dispersive plume in this case. People who were in the residential area located within the red threat zone and were indoor at the time of the spill were exposed to $2.39 \mathrm{ppm}$ of chlorine and could still suffer from irreversible or other serious, long-lasting adverse health effects or an impaired ability to escape. Barry University is located within the 2.2-mile orange threat zone. People who were out door close to Barry's University campus at the time of the spill were exposed to $15.3 \mathrm{ppm}$ of butane causing them to be at risk of suffering long-lasting adverse health effects. However, students attending classes or being indoor will be safe and potentially will not suffer from any side effects as they were exposed to $0.267 \mathrm{ppm}$, which is below the 10-min AEGL-1 value for chlorine (0.5 ppm).

Scenario (B) is a simulation to examine the extend of butane flammable area of vapor explosion. The Flammable Area analysis in ALOHA is designed to address the hazards associated with a fire or explosion of a cloud composed of a mixture of flammable chemical vapors and air in proportions that will support the propagation of a flame [5]. The flammable area represents the region where an ignition source can lead to a flash fire or vapor cloud explosion, and the area where the fire can occur. ALOHA's threat zone estimate for this scenario showing two flammable threat zones. The red threat zone represents the estimated flammable area where a flash fire or a vapor cloud explosion could occur. ALOHA estimates that the red threat zone will extend 169 yards in the downwind direction. In this zone, when the chemical vapor comes in contact with ignition source, it will burn. The yellow threat zone, which extends to 490 yards, represents the estimated area where butane concentrations could exceed $10 \%$ LEL, which indicates that flammable vapors are being released or introduced into the space and could present a hazard in time.

As mentioned earlier in the results and analysis section of this report, the more stable the atmosphere is the higher and more dangerous the concentrations are, and the longer the flammable threat zone is. When the atmosphere is stable, turbulence is minimum, flocculation in wind direction is limited, and solar radiation is little. When the atmosphere is instable it yields high turbulence, frequent flocculation in wind directions, and strong solar radiation. High turbulence means that the air is moving up and down frequently resulting in higher dispersion of chemicals present in the atmosphere, and therefore lower concentrations, and vice versa. Therefore, the optimal condition of air pollution dispersion is class A, which is the most instable atmospheric conditions. After comparing the simulation results by changing 6 different atmospheric stability classes for both scenarios, we can conclude that the stability class has a significant effect on the prediction of the size of the toxic threat zone under different atmospheric dispersion conditions [4]. In addition, the size of the area impacted after a chemical release depends on the characteristics of the chemical along with the meteorological and atmospheric conditions.

\section{References}

[1] Inanloo B. and Tansel B. (2015). Explosion impacts during transport of hazardous cargo: GIS-based characterization of overpressure impacts and delineation of flammable zones for ammonia, Journal of Environmental Management, 156: 1-9.

[2] EPA U. S. (1999). ALOHA User's Manual (Technical report). Environmental Protection Agency, Office of Energy Management. [Internet cited 25 Mar 2017]. Available from: http://www.epa.gov/emergencies/content/cameo/aloha.htm

[3] Hydro Instruments (2016). Chlorine Handling Manual. 2016. [Internet cited 8 Apr 2017] Available from: www.hydroinstruments.com/files/Chlorine $\% 2520$ Handling $\% 2$ 520Manual\%25202016\%252005\%252006.pdf $+\& \mathrm{~cd}=2 \& \mathrm{hl}=$ en $\& \mathrm{ct}=\mathrm{clnk} \& \mathrm{gl}=\mathrm{us}$

[4] Inanloo B. Tansel B. Jin X. and Bernardo -Bricker A.(2015). Cargo-specific accidental release impact zones for hazardous materials: risk and consequence comparison for ammonia and hydrogen fluoride. Environment Systems and Decisions, 36 (1): $20-33$.

[5] Jones R., Lehr W., Simecek-Beatty D. and Michael Reynolds R. (2013). ALOHA® (Areal Locations of Hazardous Atmospheres) 5.4.4: Technical Documentation. U. S. Dept. of Commerce, NOAA Technical Memorandum NOS OR\&R 43. Seattle, WA: Emergency Response Division, NOAA. 96 pp.

[6] NOAA (2011). Acute Exposure Guideline Levels (AEGLs). Office of Response and Restoration. [Internet cited $5 \mathrm{Apr}$ 2017] Available from: http://response.restoration.noaa.gov/oiland-chemical-spills/chemical-spills/resources/acute-exposureguideline-levels-aegls.html

[7] PHMSA (Pipeline and Hazardous Materials Safety Administration), US DOT (2016). [Internet cited 5 Apr 2017]. Available from:

https://phmsa.dot.gov/staticfiles/PHMSA/DownloadableFiles/ Files/Hazmat/ERG2016.

[8] Stanley S. Grossel (2008). Evaluation of the Effects and Consequences of Major Accidents in Industrial Plants (Industrial Safety Series, 8), J. Casal. Elsevier B. V., Oxford, UK/Boston, Journal of Loss Prevention in the Process Industries, 21 (4): 490-491.

[9] Tseng J. M., Su T. S. and Kuo C. Y. (2012). Consequence Evaluation of Toxic Chemical Releases by ALOHA, Procedia Engineering, 45: 384-389. 
[10] United States Department of Energy (2004). ALOHA

Computer Code Application Guidance for Documented Safety Analysis. 2004. Tech. No. DOE-EH-4.2.1. 3. [Internet cited 12 Apr 2017]. Available from:

https://energy.gov/sites/prod/files/2013/09/f2/Final ALOHA Guidance_Reportv52404.pdf

[11] United States Department of Energy (2014). ALOHA. [Internet cited 5 Apr 2017]. Available from: https://energy.gov/ehss/aloha

[12] United States Fire Administration (1998). HAZMAT for First
Responders. [Internet cited 8 Apr 2017] Available from: https://www.hsdl.org/?view\&did=1258

[13] United States Fire Administration (2017). Hazmat Intelligence Portal. U.S. Department of Transportation Pipeline and Hazardous Materials Safety Administration. [Internet cited 5 Apr 2017] Available from:

https:/hip.phmsa.dot.gov/analyticsSOAP/saw.dll?Dashboard \&NQUser=HazmatWebsiteUser1\&NQPassword=HazmatWeb siteUser1\&PortalPath=/shared/Public\%20Website\%20Pages/_ portal/Yearly\%20Incident $\% 20$ Summary\%20Reports 